\title{
Sistem Klasifikasi Otomatis Volume Balok dengan Arduino
}

\author{
Armina Syaiful Ilmi ${ }^{1}$, Mushlihudin ${ }^{2}$ \\ ${ }^{1}$ Mahasiswa Program Studi Teknik Elektro, Universitas Ahmad Dahlan, Indonesia \\ ${ }^{2}$ Dosen Program Studi Teknik Informatika, Universitas Ahmad Dahlan, Indonesia \\ Kampus IV, Jln. Ringroad Selatan, Kragilan, Tamanan, Banguntapan, Bantul, Yogyakarta 55191
}

\section{INFORMASI ARTIKEL}

\section{Riwayat:}

Dikirimkan 14 Juni 2019,

Direvisi 14 Juli 2019,

Diterima 10 Agustus 2019.

\section{Kata Kunci:}

Klasifikasi Barang,

Sensor Ultrasonik,

Motor DC,

Motor Servo,

Arduino Mega 2560.

\begin{abstract}
ABSTRAK
Penggunaan teknologi baru dan canggih menjadi pilihan dunia industri untuk meningkatkan efisiensi produksi baik dari segi kualitas, kuantitas maupun penghematan biaya. Proses otomasi sistem kendali industri tidak akan lepas dari penggunaan perangkat elektronik, seperti halnya penggunaan berbagai macam sensor dan komponen penting lainnya. Pada penelitian ini merancang prototipe konveyor yang memisahkan otomatis balok berdasarkan ukuran volume, bertujuan untuk penghematan tempat produksi kecil dan sumber daya manusia. Perancangan perangkat keras terdiri dari mikrokontroler Arduino Mega 2560 menjadi penyimpan logika perintah dalam sistem, sensor ultrasonik HC-SR04 sebagai sensor pengukur panjang, lebar dan tinggi barang, motor servo sebagai penyetop dan pemisah barang, LCD 2X16 sebagai penampil informasi dan motor dc menjadi penggerak konveyor. Pengujian sistem ini menggunakan barang penelitian 3 balok dengan ukuran berbeda yaitu $315 \mathrm{~cm}^{3}, 480 \mathrm{~cm}^{3}$ dan $525 \mathrm{~cm}^{3}$. Berdasarkan hasil pengujian menunjukkan klasifikasi volume balok dapat bekerja dengan baik, dengan tingkat rata-rata error $5,4 \mathrm{~cm}$ untuk volume ukuran $315 \mathrm{~cm}^{3} ; 3,2 \mathrm{~cm}$ untuk volume $480 \mathrm{~cm}^{3}$; dan $2,33 \mathrm{~cm}$ untuk volume $525 \mathrm{~cm}^{3}$ dan dengan standar deviasi sistem klasifikasi otomatis volume balok sebesar 9,40.
\end{abstract}

This work is licensed under a Creative Commons Attribution-Share Alike 4.0

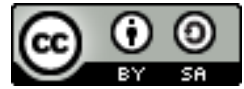

\section{Penulis Korespondensi:}

Armina Syaiful Ilmi,

Program Studi Teknik Elektro, Universitas Ahmad Dahlan,

Kampus 4 UAD, Tamanan, Banguntapan, Bantul, Yogyakarta, Indonesia.

Surel: Armina1400022012@webmail.uad.ac.id

\section{PENDAHULUAN}

Penggunaan teknologi baru dan canggih menjadi pilihan dunia industri untuk meningkatkan efisiensi produksi baik dari segi kualitas, kuantitas maupun penghematan biaya. Perkembangan teknologi yang semakin maju dan berkembang dalam dunia industri dimanfaatkan dalam pembuatan model sistem otomatisasi [1]. Pemanfaatan mikrokontroler akan banyak membawa dampak pada kemudahan dan efektivitas kerja [2]. Penggunaan teknologi mikrokontroler pada dunia industri dan jasa telah banyak digunakan. Seperti pengendali sistem konveyor dan peralatan pengukuran lainnya. Sistem konveyor merupakan teknologi untuk transportasi barang di industri dari satu bagian ke bagian yang lain, baik untuk keperluan Quality Control, pengemasan produk, perakitan dan lain-lain [3]. Mikrokontroler berfungsi sebagai pengatur kerja alat agar dapat bekerja secara sistematis [4].

Proses otomasi sistem kendali industri tidak akan lepas dari penggunaan perangkat elektronik, seperti halnya penggunaan berbagai macam sensor dan komponen penting lainnya [5]. Sensor ultrasonik adalah sebuah sensor yang berfungsi untuk mengubah besaran fisis (bunyi) menjadi besaran listrik dan sebaliknya [6]. Motor dc merupakan perangkat elektromagnetik yang mengubah energi listrik menjadi energi mekanik [7]. Motor servo merupakan salah satu jenis aktuator yang cukup banyak digunakan dalam bidang industri atau sistem robotika [8]. LCD (Liquid Cristal Display) adalah salah satu jenis penampil elektronik yang berfungsi sebagai penampil data baik dalam bentuk karakter, huruf, angka ataupun grafik [9]. 
Tujuan dari penelitian ini adalah untuk membuat prototipe konveyor klasifikasi otomatis barang berdasarkan volume barang dengan Arduino Uno. Arduino adalah platform pembuatan prototipe elektronik yang bersifat open source hardware yang berdasarkan pada perangkat keras dan perangkat lunak yang fleksibel dan mudah digunakan [10]. Agar lebih efektif dan efisien serta meminimalkan kerusakan pada barang yang diklasifikasikan dan mempermudah penyortiran.

\section{METODE PENELITIAN}

\subsection{DESAIN SISTEM}

Perancangan sistem pada penelitian ini dibuat menggunakan sebuah mikrokontroler Arduino Mega 2560 dengan menambahkan sensor Ultrasonik HC-SR04 sebagai sensor untuk pengukur panjang $(p)$, lebar $(l)$ dan tinggi $(t)$ barang. Terdapat juga infrared sebagai sensor pendeteksi barang pada ruang pengukur dan akan memberikan masukan pada motor servo menutup sebagai penyetop. kemudian sensor ultrasonik mendeteksi ukuran balok dan sistem akan mengolah data menjadi volume. Setelah tahap pengukuran volume selesai servo akan membuka dan akan menjalankan balok untuk di pisahkan menuju ruang A atau B oleh servo pemisah sesuai volume yang terukur. Selain itu terdapat Motor DC 12 Volt sebagai penggerak utama dari konveyor barang dengan kecepatan konstan dan terus menerus, serta LCD 16x2 untuk menampilkan hasil panjang $(p)$, lebar $(l)$ dan tinggi serta volume terukur. Dari perancangan sistem ini dapat dipresentasikan dalam bentuk diagram blok yang terlihat seperti pada Gambar 1.

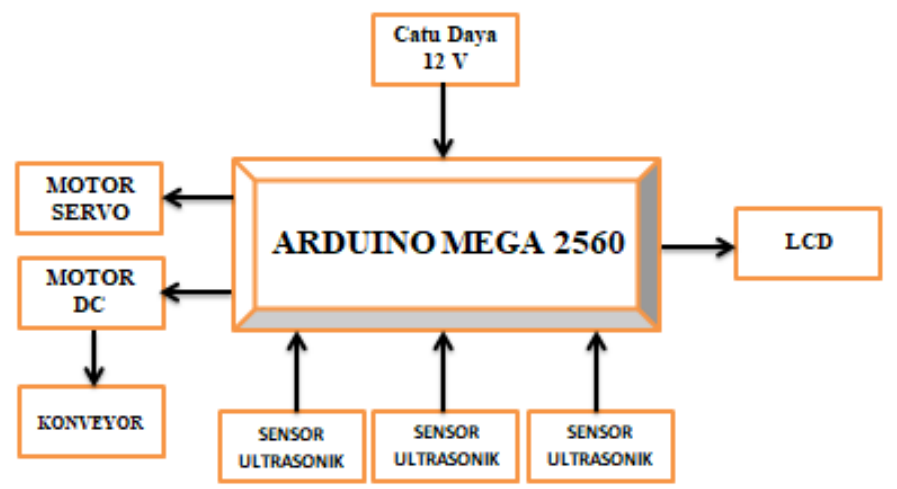

Gambar 1. Diagram blok perancangan perangkat keras

Perakitan perangkat keras merupakan proses dalam menghubungkan semua perangkat, sehingga dapat membaca nilai sensor sampai memicu kinerja nilai keluaran. Rangkaian keseluruhan sistem dapat dilihat pada Gambar 2.

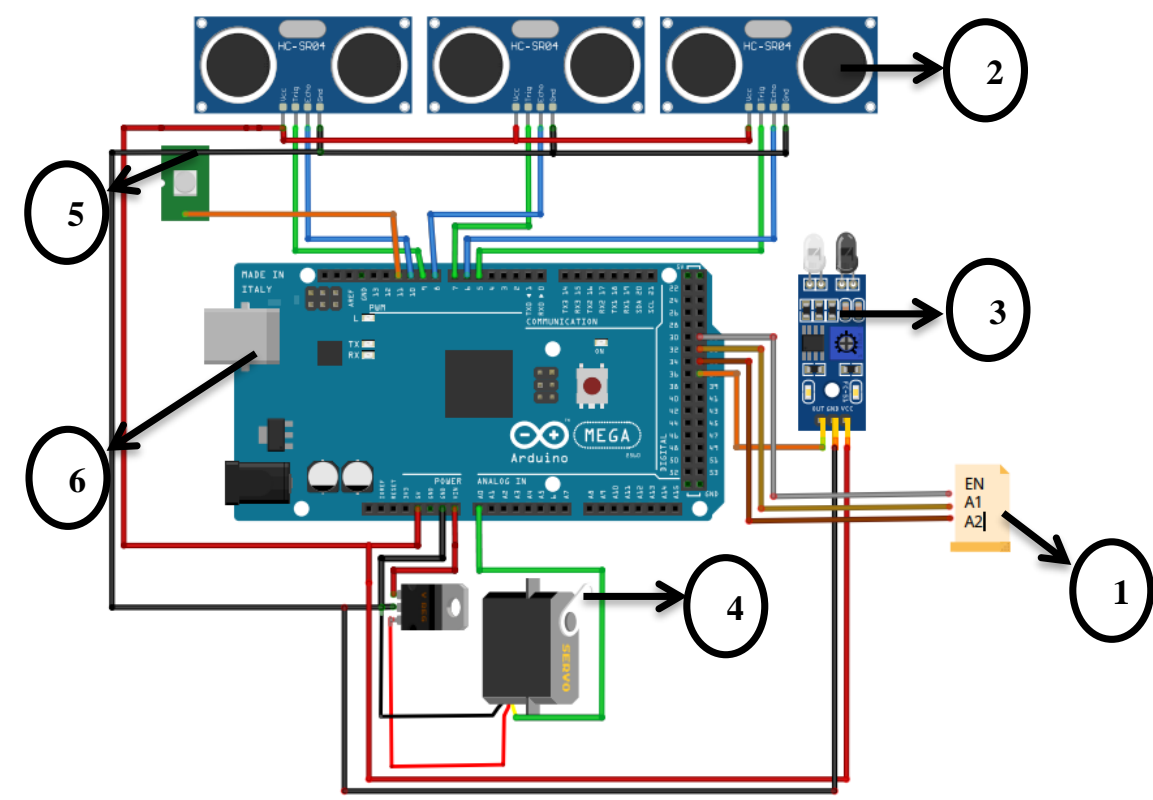

Gambar 2. Rangkaian keseluruhan sistem

Keterangan: 
1. Kontrol motor L298N

PIN yang digunakan:

- EN, IN1, IN2 adalah PIN yang terhubung ke Arduino mega sebagai kontrol PIN.

- $12 \mathrm{~V} \& \mathrm{GND}$ adalah merupakan tegangan sumber dari Power suplai.

- OUT 2 adalah keluaran untuk menggerakkan motor DC 12V.

2. Sensor ultrasonik HC-SR04

Pin yang digunakan:

- TRIGPIN adalah sebagai pembangkit sinyal

- ECHOPIN adalah sebagai sinyal pantulan dari sinyal trigger

- GND \& VCC adalah sebagai tegangan sumber

3. Infrared

Pin yang digunakan:

- GND, VCC adalah sebagai tegangan sumber

- OUT adalah keluaran untuk mendeteksi barang

4. Motor servo

Pin yang digunakan:

- GND, VCC adalah sebagai sumber tegangan

- DATA adalah sebagai kontrol digital Arduino

5. I2C/LCD $16 \times 2$

Pin yang digunakan:

- SCL adalah sebagai serial clock

- SDA adalah sebagai serial data

- GND \& VCC adalah sebagai sumber tegangan

6. Arduino mega 2560

Pin yang digunakan pada Arduino dengan komponen ditunjukkan pada Tabel 1.

Tabel 1 Pin Arduino dengan komponen

\begin{tabular}{lll}
\hline No & Komponen & Pin Pada Arduino Uno \\
\hline 1 & Driver motor L289N & ENA $=>$ D31 \\
& & IN $1=>$ D33 \\
& & TRIGPIN $=>$ PWM10 \\
\hline 2 & Sensor ultrasonik HC- & ECHOPIN $=>$ PWM9 \\
& SR04/Panjang $(p)$ & GND $=>$ GND \\
& & VCC $=>$ VCC 5V \\
\hline 3 & Sensor ultrasonik HC- & TRIGPIN $=>$ PWM8 8 \\
& SR04/Lebar $(l)$ & ECHOPIN $=>$ PWM7 \\
& & GND $=>$ GND \\
& & VCC $=>$ VCC 5V \\
\hline 4 & Sensor ultrasonik HC- & TRIGPIN $=>$ PWM6 \\
& SR04/Tinggi $(t)$ & ECHOPIN $=>$ PWM5 \\
& & GND $=>$ GND \\
& & VCC $=>$ VCC 5V \\
\hline 5 & Infra red & OUT $=>$ D37 \\
& & GND $=>$ GND \\
& & VCC $=>$ VCC 5V \\
\hline 6 & Motor servo 1 & DATA $=>$ A2 \\
& & VCC $=>$ VCC 5V \\
& & GND $=>$ GND \\
\hline 7 & Motor servo 2 & DATA $=>$ A1 \\
& & VCC $=>$ VCC 5V \\
& & GND $=>$ GND \\
\hline 8 & LCD menggunakan I2C & SCL $=>$ SCL \\
& & SDA $=>$ SDA \\
& & VCC $=>5 \mathrm{~V}$ \\
\hline \multirow{4}{*}{} & & GND $=>$ GND \\
\hline &
\end{tabular}

Perancangan konstruksi alat dibuat sedemikian rupa agar sistem berjalan sesuai dengan tujuan. Adapun perancangan konstruksi alat ditunjukkan pada Gambar 3 dan Gambar 4. Perancangan alat tampak samping ditunjukkan pada Gambar 3 sementara perancangan alat tampak atas ditunjukkan pada Gambar 4. 


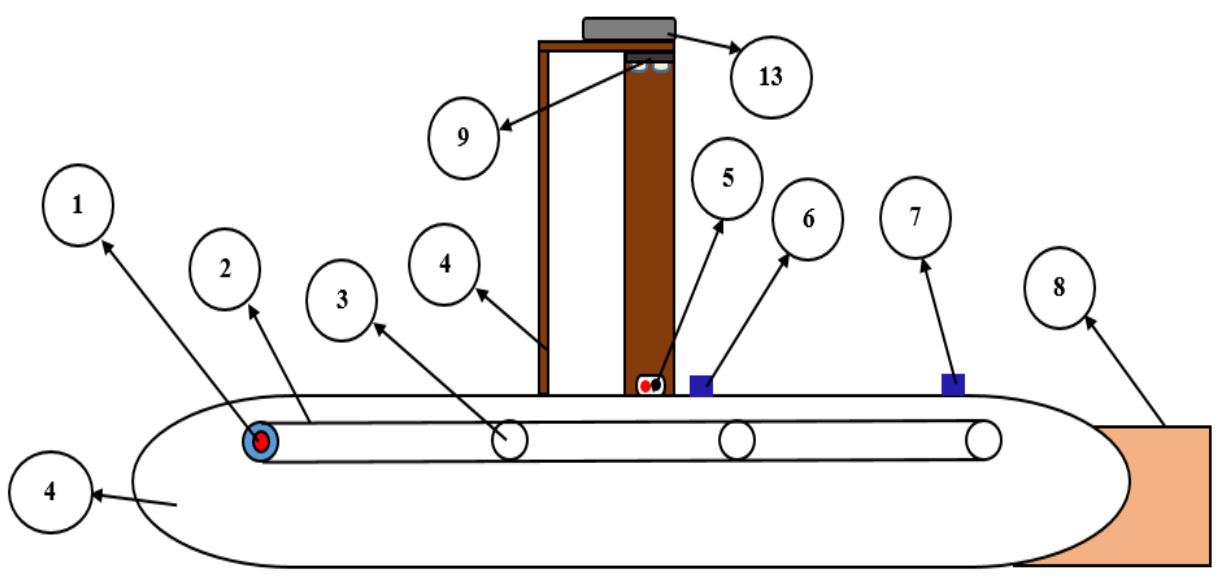

Gambar 3. Perancangan Alat tampak samping

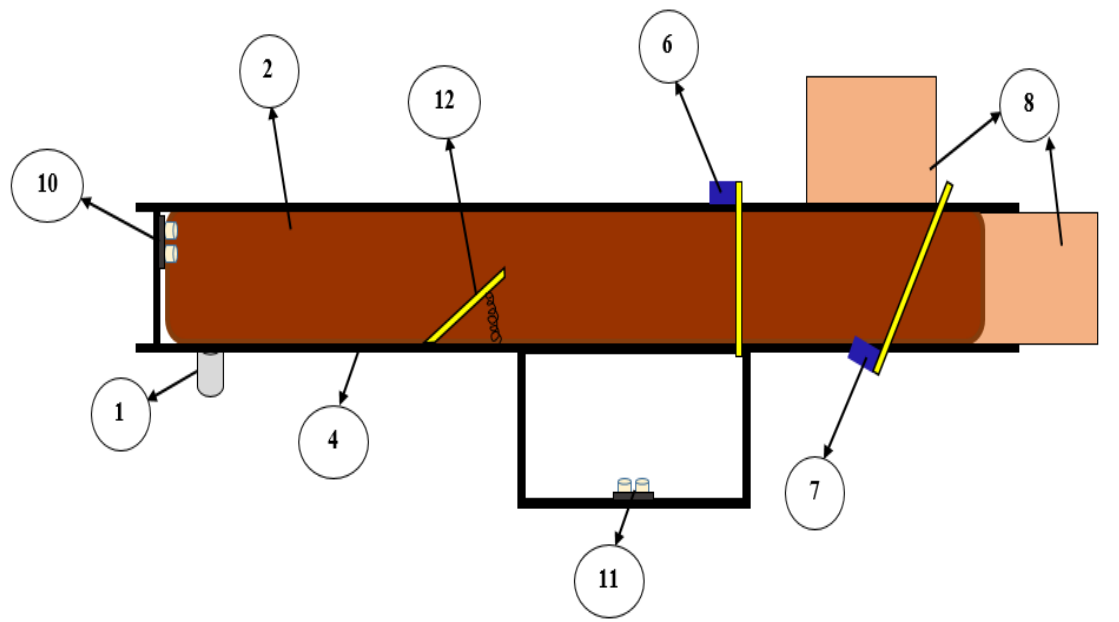

Gambar 4. Perancangan Alat tampak atas

Keterangan:

Pada perancangan konstruksi alat Gambar 3 dan Gambar 4 menggunakan rangka kayu dengan panjang $85 \mathrm{~cm}$ lebar $20 \mathrm{~cm}$ dan tinggi $40 \mathrm{~cm}$. Dengan panjang belt conveyor $60 \mathrm{~cm}$ pada nomor 2 yang digerakkan motor DC $12 \mathrm{~V}$ pada nomor 1 dan berjalan searah dengan 4 roller belt pada nomor 3 . Setelah barang masuk dan berjalan di atas belt conveyor kemudian barang akan ditekan menggunakan pegas pendorong barang pada nomor 4 agar barang di posisi kiri. Setelah itu infra red pada nomor 5 akan mendeteksi barang dan motor servo penyekat nomor 6 akan bergerak turun dan belt conveyor akan berhenti sementara. Pada saat belt berhenti ketiga sensor Ultrasonik pada nomor 9, 10 dan 11 akan menghitung nilai panjang, lebar dan tinggi dan akan menampilkan nilai volume pada LCD nomor 13. Setelah volume muncul pada LCD, servo penyekat akan naik dan barang akan di pisahkan oleh servo pemisah nomor 7 sesuai volume terukur pada Box A maupun Box B.

\subsection{ALGORITMA}

Setelah perancangan perangkat keras selesai dikerjakan, maka langkah selanjutnya adalah perancangan perangkat lunak (program perintah). Perancangan perangkat lunak menggunakan software Arduino. Hal yang perlu dilakukan terlebih dahulu sebelum membuat program adalah membuat diagram alir (flowchart) sebagai panduan penulisan program. Flowchart dapat dilihat pada Gambar 5. 


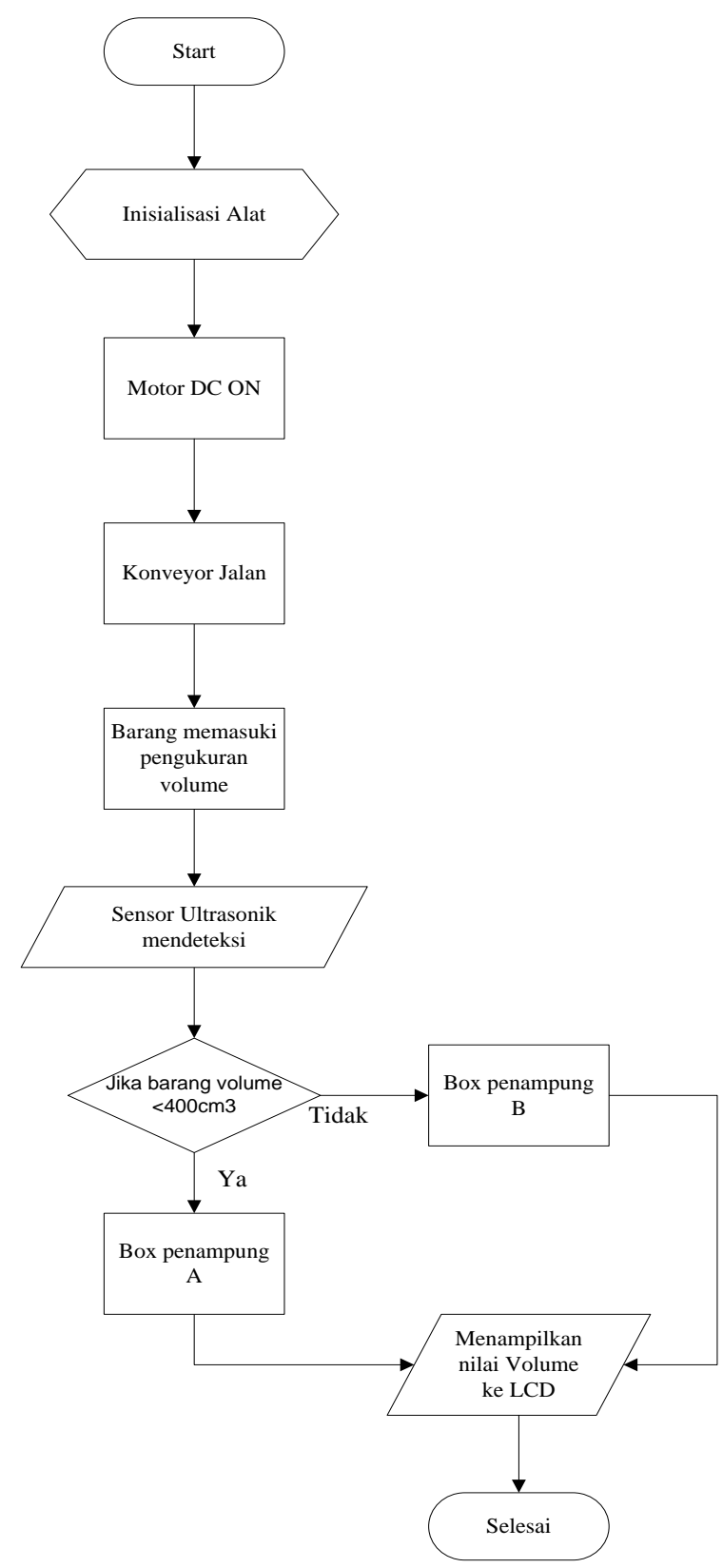

Gambar 5 flowchart atau diagram alir sistem

Ketika sistem dihidupkan maka akan menyalakan layar LCD untuk menampilkan informasi pembuka berupa sistem klasifikasi ukuran barang. Selanjutnya motor dc akan bergerak untuk menjalankan konveyor pemindah barang, konveyor berjalan konstan secara terus menerus dan akan berhenti setelah barang terdeteksi oleh Infrared (IR). Setelah Infrared (IR) bekerja maka 3 sensor akan membaca barang yang berada diatas conveyor. Setelah volume barang terukur atau membaca ukuran $\left(400 \mathrm{~cm}^{3}\right.$ sebagai ambang batas karena ukuran setandar atau ukuran yang terbaik yang digunakan pada sistem adalah $400 \mathrm{~cm}^{3}$ ), maka conveyor akan kembali berjalan dan barang akan dipisahkan atau diklasifikasikan oleh motor servo sesuai volume barang yang diukur dan akan masuk pada box sesuai volume yang dibaca oleh sensor. Pada sistem ini menggunakan 3 buah barang dengan ukuran volume berbeda dan hanya dengan menggunakan 2 buah box penampung dikarenakan sebagai sampel ukuran volume barang yang melebihi ambang batas ukuran standar apakah akan berhasil diukur atau tidak. Setelah eksekusi perintah selesai maka motor servo akan kembali ke posisi semula untuk melakukan perintah lainnya.

\section{HASIL DAN PEMBAHASAN}

Setelah melakukan proses perancangan software dan hardware selesai, maka tahap selanjutnya adalah melakukan analisis data. Analisis data digunakan untuk menganalisis data yang dihasilkan oleh sistem klasifikasi ukuran barang. Data yang dihasilkan yaitu data nilai panjang $(p)$, lebar $(l)$ dan tinggi $(t)$ oleh 
pembacaan sensor ultrasonik terhadap barang yang diukur setelah diolah mikrokontroler. Analisis data yang digunakan untuk sistem secara keseluruhan adalah analisis akurasi dengan mencari rata-rata error dan standar deviasi. Untuk menghitung nilai rata-rata error dan standar deviasi menggunakan persamaan berikut.

Perhitungan yang digunakan untuk menghitung error:

$$
\text { Error }=(\text { Hasil volume terukur penggaris }- \text { Hasil volume terukur alat })
$$

Keterangan:

Hasil volume penggaris = hasil pengukuran volume balok dengan penggaris atau secara manual.

Hasil volume terukur $=$ volume dari hasil pengukuran sistem klasifikasi ukuran barang

Perhitungan yang digunakan untuk menghitung error rata-rata:

$$
\text { Rata }- \text { rata error }=\frac{\text { error } 1+\text { error } 2+\text { error } 3 \ldots . . \text { error } n}{\text { jumlah data }}
$$

Keterangan:

Error1 dst $=$ nilai error pada tiap percobaan

Jumlah data = jumlah keseluruhan data yang diambil

Perhitungan yang digunakan untuk menghitung nilai deviasi:

$$
\mathrm{d}=\text { error }-(\text { error } \text { rata }- \text { rata })
$$

Perhitungan yang digunakan untuk menghitung standar deviasi secara umum adalah sebagai berikut:

$$
\operatorname{Standar} \operatorname{deviasi}(\sigma)=\sqrt{\frac{\sum \mathrm{d} n}{\mathrm{n}-1}}
$$

Keterangan:

$$
\begin{aligned}
& \mathrm{s}=\text { standar deviasi } \\
& \mathrm{d}=\text { nilai deviasi setiap percobaan } \\
& \mathrm{n}=\text { banyaknya data percobaan }
\end{aligned}
$$

Berdasarkan analisa dan perancangan sistem yang dijelaskan, maka perlu dilakukan pengujian terhadap sistem yang telah direncanakan dan dibuat. Tujuan dari pengujian ini adalah untuk mengetahui apakah sistem yang dibuat sudah sesuai dengan perencanaan atau belum serta untuk mendapatkan data dari sistem tersebut, sehingga dengan diperolehnya data dapat diketahui kinerja dari sistem yang telah dirancang.

Setiap metode pengambilan data dilakukan sebanyak 15 kali percobaan. Kemudian dari data hasil pengujian tersebut akan dihitung persentase keberhasilannya untuk menentukan alat yang dibuat tersebut telah sesuai atau belum dengan tujuan pembuatan. Hasil dari data yang diambil akan dicari presentase error dan nilai deviasi atau simpangan hasil pengukuran secara manual atau dengan penggaris dibanding dengan hasil dari pengukuran alat ukur sistem klasifikasi ukuran barang.

\subsection{KLASIFIKASI UKURAN BARANG A}

Pengambilan data barang A dilakukan sebanyak 15 kali kemudian dari data yang diambil akan dihitung nilai error, rata-rata error dan nilai deviasi. Adapun data hasil tampilan LCD untuk volume $315 \mathrm{~cm}^{3}$ pada Gambar 6.

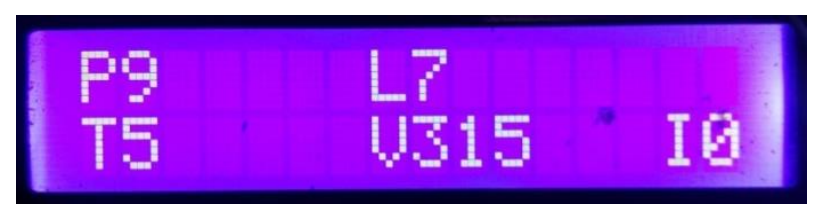

Gambar 6 Tampilan sampel LCD untuk nilai volume $315 \mathrm{~cm}^{3}$

Pengujian klasifikasi ukuran barang setelah dilakukan 15 kali percobaan maka di dapat hasil pengukuran barang A dengan volume $315 \mathrm{~cm}^{3}$ seperti ditampilkan pada Tabel 2. 
Tabel 2 Pengukuran barang A dengan konveyor klasifikasi barang

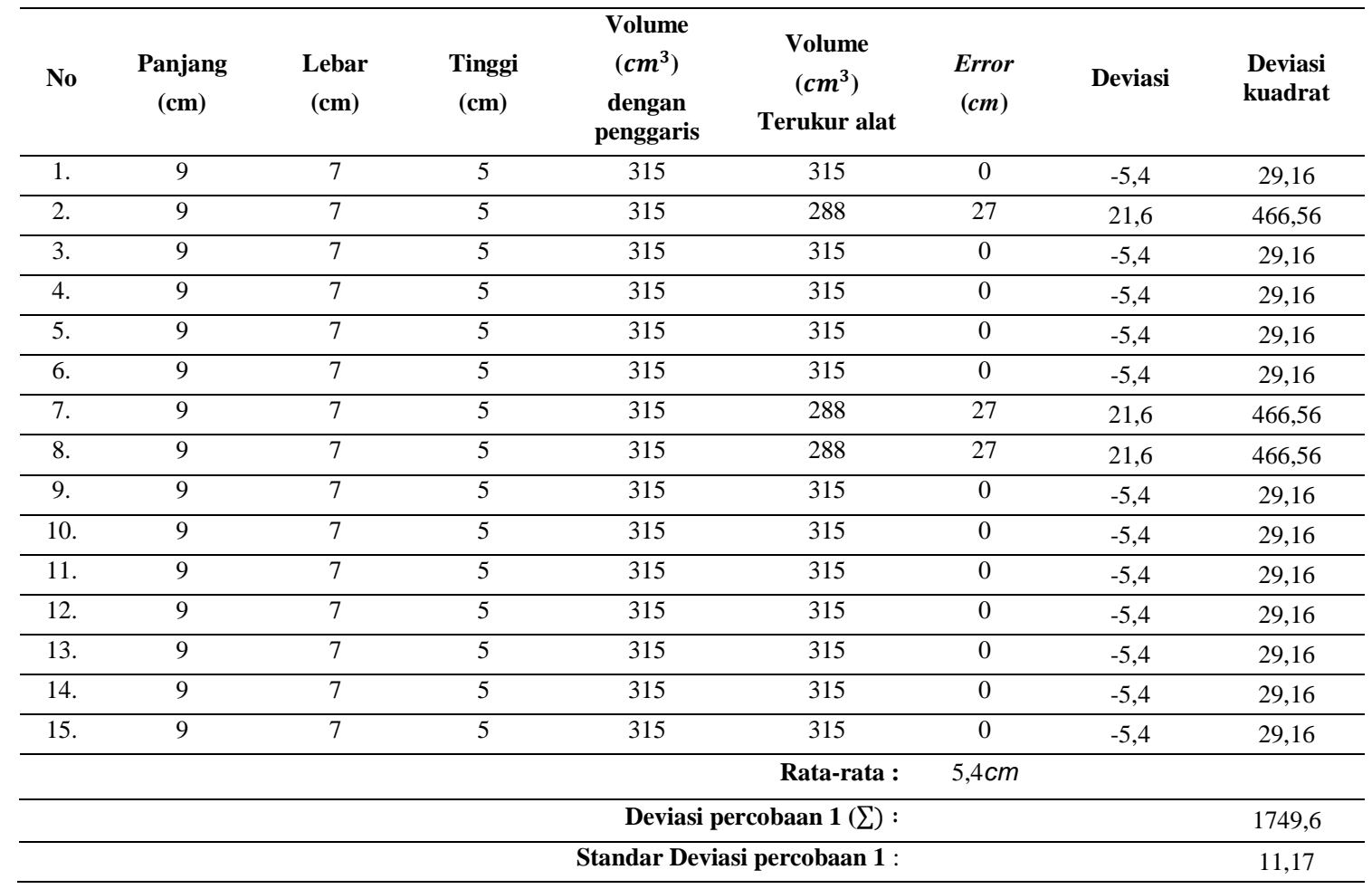

\subsection{KLASIFIKASI UKURAN BARANG B}

Pengambilan data barang B dilakukan sebanyak 15 kali kemudian dari data yang diambil akan dihitung nilai error, rata-rata error dan nilai deviasi. Adapun data hasil tampilan LCD untuk volume $480 \mathrm{~cm}^{3} \mathrm{pada}$ Gambar 7.

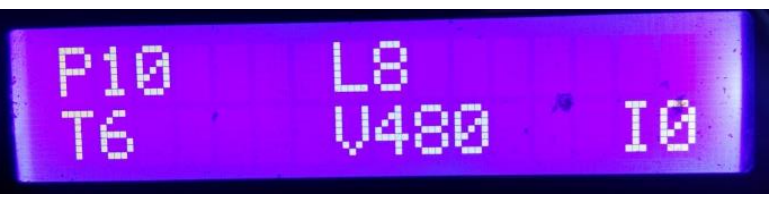

Gambar 7 Tampilan sampel LCD untuk nilai volume $480 \mathrm{~cm}^{3}$

Pengujian klasifikasi ukuran barang setelah dilakukan 15 kali percobaan maka di dapat hasil pengukuran barang B dengan volume $480 \mathbf{c m}^{3}$ seperti ditampilkan pada Tabel 3

Tabel 3 Pengukuran barang B dengan conveyor klasifikasi barang

\begin{tabular}{|c|c|c|c|c|c|c|c|c|}
\hline No & $\begin{array}{c}\text { Panjang } \\
\quad(\mathrm{cm})\end{array}$ & $\begin{array}{c}\text { Lebar } \\
(\mathrm{cm})\end{array}$ & $\begin{array}{c}\text { Tinggi } \\
\text { (cm) }\end{array}$ & $\begin{array}{c}\text { Volume } \\
\left(\mathrm{cm}^{3}\right) \\
\text { dengan } \\
\text { penggaris }\end{array}$ & $\begin{array}{c}\text { Volume } \\
\left(\mathrm{cm}^{3}\right) \\
\text { Terukur alat }\end{array}$ & $\begin{array}{c}\text { Error } \\
(\mathrm{cm})\end{array}$ & Deviasi & $\begin{array}{c}\text { Deviasi } \\
\text { Kuadrat }\end{array}$ \\
\hline 1. & 10 & 6 & 8 & 480 & 480 & 0 & $-3,2$ & 10,24 \\
\hline 2. & 10 & 6 & 8 & 480 & 480 & 0 & $-3,2$ & 10,24 \\
\hline 3. & 10 & 6 & 8 & 480 & 480 & 0 & $-3,2$ & 10,24 \\
\hline 5. & 10 & 6 & 8 & 480 & 504 & 24 & 20,8 & 432,64 \\
\hline 6. & 10 & 6 & 8 & 480 & 480 & 0 & $-3,2$ & 10,24 \\
\hline 7. & 10 & 6 & 8 & 480 & 480 & 0 & $-3,2$ & 10,24 \\
\hline 8. & 10 & 6 & 8 & 480 & 504 & 24 & 20,8 & 432,64 \\
\hline 9. & 10 & 6 & 8 & 480 & 480 & 0 & $-3,2$ & 10,24 \\
\hline
\end{tabular}




\begin{tabular}{|c|c|c|c|c|c|c|c|c|}
\hline No & $\begin{array}{c}\text { Panjang } \\
(\mathrm{cm})\end{array}$ & $\begin{array}{l}\text { Lebar } \\
(\mathrm{cm})\end{array}$ & $\begin{array}{c}\text { Tinggi } \\
\text { (cm) }\end{array}$ & $\begin{array}{c}\text { Volume } \\
\left(\mathrm{cm}^{3}\right) \\
\text { dengan } \\
\text { penggaris }\end{array}$ & $\begin{array}{c}\text { Volume } \\
\left(\mathrm{cm}^{3}\right) \\
\text { Terukur alat }\end{array}$ & $\begin{array}{c}\text { Error } \\
(\mathrm{cm})\end{array}$ & Deviasi & $\begin{array}{c}\text { Deviasi } \\
\text { Kuadrat }\end{array}$ \\
\hline 11. & 10 & 6 & 8 & 480 & 480 & 0 & $-3,2$ & 10,24 \\
\hline 12. & 10 & 6 & 8 & 480 & 480 & 0 & $-3,2$ & 10,24 \\
\hline 13. & 10 & 6 & 8 & 480 & 480 & 0 & $-3,2$ & 10,24 \\
\hline 14. & 10 & 6 & 8 & 480 & 480 & 0 & $-3,2$ & 10,24 \\
\hline \multirow[t]{4}{*}{15.} & 10 & 6 & 8 & 480 & 480 & 0 & $-3,2$ & 10,24 \\
\hline & & & & & Rata-rata : & $3,2 \mathrm{~cm}$ & & \\
\hline & & & & Deviasi & cobaan $2\left(\sum\right):$ & & & 998,4 \\
\hline & & & & Standar Des & percobaan 2 & & & 8,44 \\
\hline
\end{tabular}

\subsection{KLASIFIKASI UKURAN BARANG C}

Pengambilan data barang $\mathrm{C}$ dilakukan sebanyak 15 kali kemudian dari data yang diambil akan dihitung nilai error, rata-rata error dan nilai deviasi. Adapun data hasil tampilan LCD untuk volume $525 \mathrm{~cm}^{3}$ ditunjukkan pada Gambar 8.

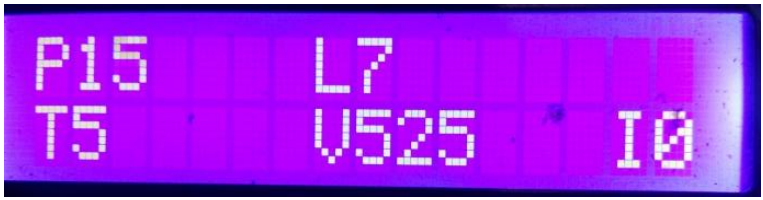

Gambar 8 Tampilan sampel LCD untuk nilai volume $525 \mathrm{~cm}^{3}$

Pengujian klasifikasi ukuran barang setelah dilakukan 15 kali percobaan diperoleh hasil pengukuran barang $\mathrm{C}$ dengan volume $525 \mathrm{~cm}^{3}$ yang ditampilkan pada Tabel 4 .

Tabel 4 Pengukuran barang $\mathrm{C}$ dengan conveyor klasifikasi barang

\begin{tabular}{|c|c|c|c|c|c|c|c|c|}
\hline No & $\begin{array}{c}\text { Panjang } \\
\text { (cm) }\end{array}$ & $\begin{array}{c}\text { Lebar } \\
(\mathrm{cm})\end{array}$ & $\begin{array}{l}\text { Tinggi } \\
\text { (cm) }\end{array}$ & $\begin{array}{c}\text { Volume } \\
\left(\mathrm{cm}^{3}\right) \\
\text { Dengan } \\
\text { penggaris }\end{array}$ & $\begin{array}{c}\text { Volume } \\
\left(\mathrm{cm}^{3}\right) \\
\text { Terukur alat }\end{array}$ & $\begin{array}{l}\text { Error } \\
(\mathrm{cm})\end{array}$ & Deviasi & $\begin{array}{l}\text { Deviasi } \\
\text { kuadat }\end{array}$ \\
\hline 1. & 15 & 7 & 5 & 525 & 525 & 0 & $-2,33$ & 5,42 \\
\hline 2. & 15 & 7 & 5 & 525 & 525 & 0 & $-2,33$ & 5,42 \\
\hline 3. & 15 & 7 & 5 & 525 & 525 & 0 & $-2,33$ & 5,42 \\
\hline 4. & 15 & 7 & 5 & 525 & 525 & 0 & $-2,33$ & 5,42 \\
\hline 5. & 15 & 7 & 5 & 525 & 525 & 0 & $-2,33$ & 5,42 \\
\hline 6. & 15 & 7 & 5 & 525 & 525 & 0 & $-2,33$ & 5,42 \\
\hline 7. & 15 & 7 & 5 & 525 & 490 & 35 & 32,7 & 1069,29 \\
\hline 8. & 15 & 7 & 5 & 525 & 525 & 0 & $-2,33$ & 5,42 \\
\hline 9. & 15 & 7 & 5 & 525 & 525 & 0 & $-2,33$ & 5,42 \\
\hline 10. & 15 & 7 & 5 & 525 & 525 & 0 & $-2,33$ & 5,42 \\
\hline 11. & 15 & 7 & $5 \mathrm{~cm}$ & 525 & 525 & 0 & $-2,33$ & 5,42 \\
\hline 12. & 15 & 7 & $5 \mathrm{~cm}$ & 525 & 525 & 0 & $-2,33$ & 5,42 \\
\hline 13. & 15 & 7 & $5 \mathrm{~cm}$ & 525 & 525 & 0 & $-2,33$ & 5,42 \\
\hline 14. & 15 & 7 & $5 \mathrm{~cm}$ & 525 & 525 & 0 & $-2,33$ & 5,42 \\
\hline 15. & 15 & 7 & $5 \mathrm{~cm}$ & 525 & 525 & 0 & $-2,33$ & 5,42 \\
\hline & & & & & Rata-rata : & $2,33 \mathrm{~cm}$ & & \\
\hline \multicolumn{8}{|c|}{ Deviasi percobaan $3(\Sigma)$ : } & 1145,17 \\
\hline \multicolumn{8}{|c|}{ Standar Deviasi percobaan 3 : } & 9,04 \\
\hline
\end{tabular}


Hasil dari pengujian 3 barang berbentuk balok dengan ukuran berbeda di atas dapat diketahui tingkat Error perhitungan sistem untuk mengukur panjang (p), lebar (l) dan tinggi (t) sehingga secara signifikan dapat mempengaruhi nilai Volume yang terukur. Pada barang pertama dengan ukuran sebenarnya yaitu $315 \mathrm{~cm}^{3}$ dan terhitung nilai rata-rata error pembacaan alat yaitu sebesar 5,4cm. kemudian pada balok kedua dengan Volume sebenarnya $480 \mathrm{~cm}^{3}$ diketahui nilai rata-rata error sebesar $3,2 \mathrm{~cm}$. Pada pengujian terakhir yaitu menggunakan barang berupa balok dengan ukuran $525 \mathrm{~cm}^{3}$ bisa diketahui rata-rata error sebesar $2,33 \mathrm{~cm}$. Berdasarkan ketiga tabel data balok $\mathrm{A}$, balok $\mathrm{B}$ dan balok $\mathrm{C}$ tersebut dihitung nilai standar deviasi dari ketiga data tabel pengukuran balok A,B dan $\mathrm{C}$ di atas berikut untuk mencari nilai standar deviasi seperti pada Tabel 5.

Tabel 5 Standar deviasi dari ketiga percobaan

\begin{tabular}{ccc}
\hline $\begin{array}{c}\text { Percobaan } \\
\text { Ke- }\end{array}$ & Deviasi kuadrat & $\begin{array}{c}\text { Standar Deviasi setiap } \\
\text { percobaan }\end{array}$ \\
\hline 1 & 1749,6 & 11,17 \\
\hline 2 & 998,4 & 8,44 \\
\hline 3 & 1145,17 & 9,04 \\
\hline Deviasi $\left(\sum\right):$ & 3893,17 & \\
\hline
\end{tabular}

Untuk mencari standar deviasi dari nilai deviasi keseluruhan percobaan dengan menggunakan Persamaan 4. Hasil perhitungan standar deviasi adalah sebagai berikut.

$$
\text { Standar deviasi }(\sigma)=\sqrt{\frac{\sum \mathrm{d}}{\mathrm{n}-1}}=\sqrt{\frac{3893,17}{44}}=9,40
$$

Berdasarkan hasil perhitungan standar deviasi ketiga percobaan bernilai sebesar 9,40. Dari nilai standar deviasi tersebut disimpulkan bahwa semakin besar nilai standar deviasi maka akan semakin besar pula variasi rentang datanya. Sedangkan jika nilai standar deviasi semakin kecil maka akan semakin mendekati rata-rata. Jadi standar deviasi yang baik adalah standar deviasi yang sedikit rendah atau mendekati nilai 0 (nol). Berdasarkan standar deviasi setiap percobaan pada Tabel 5, percobaan ke 2 mempunyai hasil yang paling kecil. Hal tersebut disebabkan karena sisi panjang, lebar dan tinggi barang pada percobaan 2 memiliki panjang sisi yang lebih kompleks diukur oleh sistem.

\section{KESIMPULAN}

Setelah dilakukan pengujian terhadap perancangan dan pembuatan sistem klasifikasi ukuran barang dengan arduino, sistem dapat menjalankan perintah klasifikasi ukuran barang berdasarkan volume yang terukur. Dengan 3 balok ukuran volume ukuran $315 \mathrm{~cm}^{3}$ dengan nilai error $5,4 \mathrm{~cm}$, volume ukuran $480 \mathrm{~cm}^{3}$ dengan error $3,2 \mathrm{~cm}$ dan volume ukuran $525 \mathrm{~cm}^{3}$ dengan error $2,33 \mathrm{~cm}$ dan dengan standar deviasi sistem klasifikasi ukuran barang dengan arduino sebesar $\sigma=9,40$ sudah mampu untuk mengklasifikasikan barang berupa balok sesuai ukuran volume yang terukur pada box A dan box B.

\section{UCAPAN TERIMA KASIH}

Terima kasih tak lupa penulis ucapkan kepada editor dan reviewer atas semua saran dan masukkan serta kepada semua pihak yang terkait dalam penyelesaian jurnal ini. Semoga kebaikan yang telah diberikan kepada penulis dapat menjadi amal ibadah dengan balasan pahala dari Allah SWT. Penulis mengharapkan agar tugas akhir ini dapat dimanfaatkan dengan sebaik-baiknya guna menambah ilmu pengetahuan khususnya bagi para pembaca pada umumnya.

\section{REFERENSI}

[1] Hermawati, W. Euis, H. Witarsa, M. Verdian, D. Yuniarti, and Caroline, "Prototipe Penyortir Barang Berdasarkan Warna, Bentuk dan Tinggi Berbasis Programmable Logic Controller (PLC) dengan Penggerak Sistem Pneumatic," Jurnal Mikrotiga, vol. 1, no. 2, pp. 8-13, 2014.

[2] D. Prihatmoko, "Perancangan Dan Implementasi Pengontrol Suhu Ruangan Berbasis Mikrokontroller Arduino Uno," Simetris: J. Tek. Mesin, Elektro dan Ilmu Komputer, vol. 7, no. 1, p. 117, 2017.

[3] A. Mubyarto, W. Hp, A. Taryana, and M. Munawar, "Sistem Pemisah Benda Berdasarkan Warna, Ukuran Dan Jenis Benda Berbasis Plc Mitsubishi Fx2n," Techno (Jurnal Fakultas Teknik, Universitas Muhammadiyah Purwokerto), vol. 18, no. 1, pp. 7-14, 2017.

[4] D. Nur'ainingsih and I. T. Handoyo, "Sistem Kendali Conveyor Otomatis Automatic Conveyor Control System Based on AT89S51 Microcontroller,” J. Elektum, vol. 2, no. 3, pp. 202-212, 2010.

[5] E. Gunawan and A. B. Maulana, "Rancang Bangun Prototype Sistem Penyortiran Barang Melalui Kode Warna (Ourcode) Berbasis Arduino Uno," J. Cahaya Bagaskara, vol. 1, no. 1, pp. 22-29, 2017.

[6] A. D. Limantara, Y. Cahyo, S. Purnomo, and S. W. Mudjanarko, "Pemodelan Sistem Pelacakan LOT Parkir Kosong Berbasis Sensor Ultrasonic Dan Internet Of Things ( IOT ) Pada Lahan Parkir Diluar Jalan," Semin. Nas. Sains dan Teknol., vol. 1, no. 2, pp. 1-10, 2017.

[7] R. Birdayansyah, N. Sudjarwanto, and O. Zebua, "Pengendalian Kecepatan Motor DC Menggunakan Perintah Suara 
Berbasis Mikrokontroler Arduino,” J. Rekayasa dan Teknol. Elektro, vol. 9, no. 2, pp. 97-107, 2015.

[8] P. Prasetyawan, Y. Ferdianto, S. Ahdan, and F. Trisnawati, "Pengendali Lengan Robot Dengan Mikrokontroler Arduino Berbasis Smartphone," J. Tek. Elektro ITP, vol. 7, no. 2, pp. 104-109, 2018.

[9] R. Rohmayanti, "Otomatisasi Penghitung Jumlah Barang Secara Random Dengan Sensor Ultrasonik HC-SR04 Berbasis Mikrokontroler Arduino UNO,” 2017.

[10] A. Akhiruddin, "Perancangan Alat Pemisah dan Pensortir Buah Jeruk Berbasis Arduino," J. Electr. Technol., vol. 2 , no. 3, pp. 35-43, 2017.

\section{BIOGRAFI PENULIS}

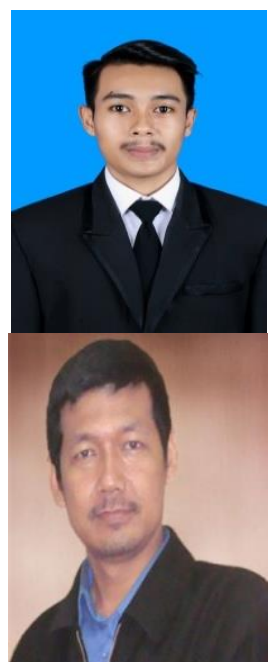

Armina Syaiful 'Ilmi

Lahir di Bantul tanggal 24 Mei 1996. Menyelesaikan pendidikan S1 Teknik Elektro di Universitas Ahmad Dahlan Yogyakarta.

\section{Mushlihudin, S.T., M.T}

Menyelesaikan pendidikan S1 Teknik Elektro di Universitas Gajah Mada Yogyakarta, S2 di Institut Teknologi Bandung. Bidang keahlian yang diminati beliau Security, Web dan Networking. Saat ini beliau menjabat sebagai Asisten Ahli/III.C program studi Teknik Informatika Universitas Ahmad Dahlan Yogyakarta. 